\title{
TRITICUM AESTIVUM(WHEAT GRASS); A POWER HOUSE PLANT - A REVIEW
}

\author{
Sanjeevini A.Hattarki', Chetna. Bogar ${ }^{2}$
}

${ }^{1}$ MDS, Maratha Mandal institute of Dental sciences and Research Centre, Karnataka, India

${ }^{2}$ BDS, M.Sc, Oral Biology Maratha Mandal institute of Dental sciences and Research Centre, Karnataka, India

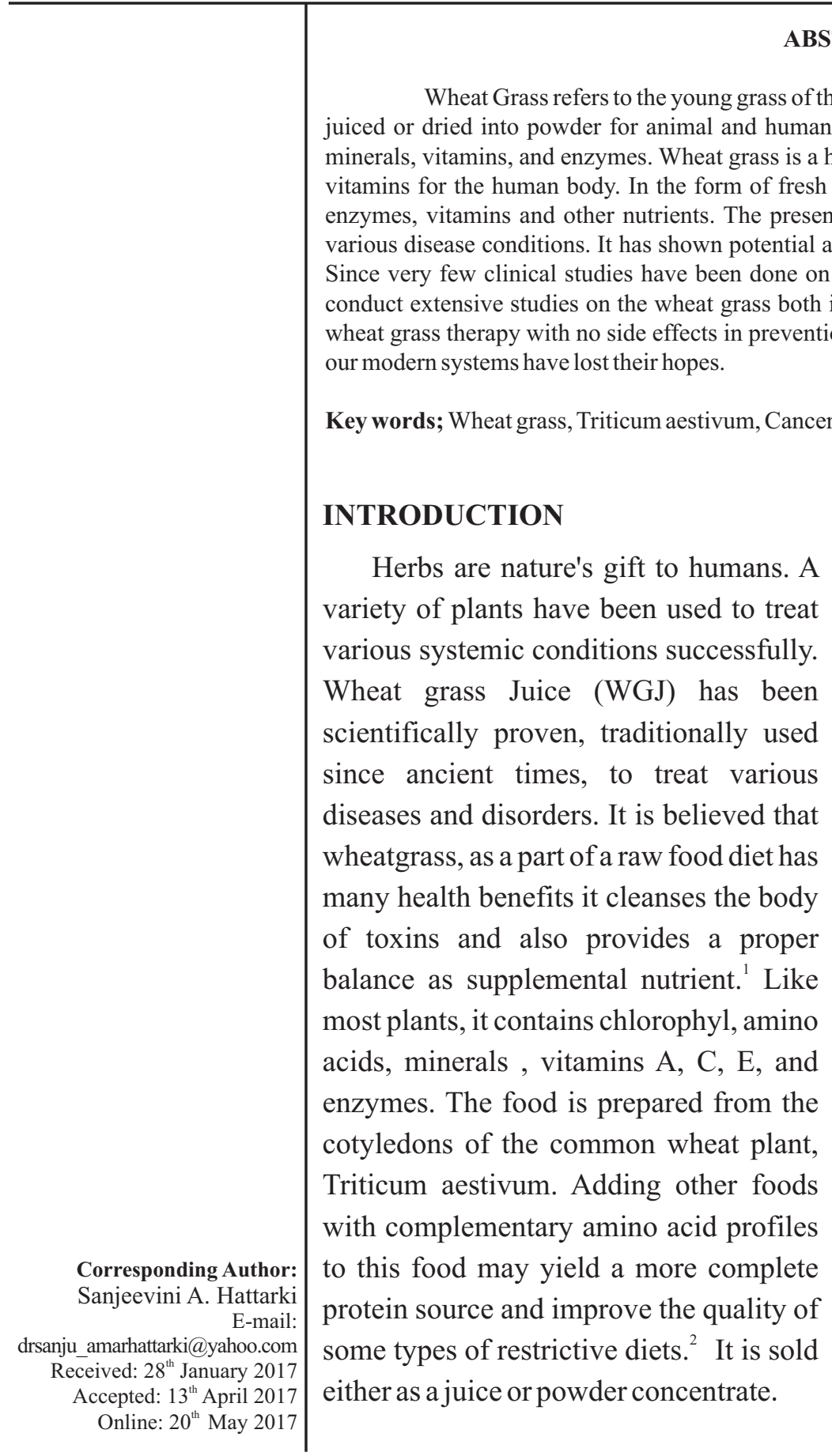

\section{ABSTRACT}

on wheat plant, Triticum aestivum that is freshly juiced or dried into powder for animal and human consumption. Both provide chlorophyll, amino acids, minerals, vitamins, and enzymes. Wheat grass is a humble weed known as the powerhouse of nutrients and vitamins for the human body. In the form of fresh juice, it has high concentrations of chlorophyll, active enzymes, vitamins and other nutrients. The present review article focuses onto the use of wheatgrass in thown potential anti inflammatory, anti oxidant and anti ageing property this very promising herbal drug, efforts are needed to wheat grass therapy with no side effects in prevention, cure and management of chronic diseases for which Key words; Wheat grass, Triticum aestivum, Cancer, Gum Disease

Triticum aestivum that germinates over a period of 6 to 10 days is generally called wheat grass. During germination/ sprouting, extensive changes occur in the seeds where in compounds such as vitamins and phenolic synthesis occurs. The nutritional value of wheat grass increases with the germination period and reaches a maximum on day 7 of growth (Hanninen et al.1999).

The founder of the Hippocrates Health Institute Dr. Ann Wigmore (1985), believed that wheatgrass, as a part of a raw food diet is used for therapeutic purposes and also can be used in halitosis, body odor. $^{3}$

\section{Description of tritium aestivum}

Tritium aestivum belongs to the family Gramineae and the Genus known as Triticum and Species Aestivum commonly known as wheat grass that contains the following chemical 
constituents. $^{4-7}$

1. Vitamins and minerals: Vitamins A, B1, 2, 3, 5, 6, 8, and $12 ; \mathrm{C}, \mathrm{E}$ and $\mathrm{K}$, ascorbic acid, dehydrated ascorbic acid, sodium, alumenium, carotene, sulfur, copper, calcium, iodine, phosphorus, magnesium, alkaline earth metal, potassium, selenium, Iron, Zinc, boran and molybdenum.

2. Enzymes: Protease, transhydrogenase,lypase, amylase, cytochrome oxidase, superoxide dismutase (SOD)

3. Other special components: Amino acids such as aspartic acid, threonine, asparagines, glutamine, proline, glycine, arginine, alanine, valine, methionine, isoleucine, leucine, tyrosine, phenylalanine, lysine, histidine, tryptophan and serine, P4D1 (gluco-protein), muco-polysaccharides, and chlorophyll, bioflavonides like apigenin, quercitin and luteonin, indole compounds, choline and laetrile (amygdalin).

\section{Wheatgrass for general well being}

Wheatgrass loaded with vitamins acts as an antioxidant and retards ageing of cells in the body that causes brain and heart problems. Components of wheatgrass has various effective role such as, an effective tonic, beneficial in arthritis, skin allergies, graying or hair loss, weakness, kidney stones, weak eyesight, pyorrhea, or dental infections and fatigue. It is also super effective in serious cases of heart disease, acute stomach ache, infection of digestive system, gas, paralysis, asthma, constipation, diabetes, leucoderma, leukemia, and other cancers. ${ }^{8}$ It restores fertility and promotes youthfulness because the high magnesium content in chlorophyll builds enzymes that restore sex hormones also it makes help menopause more manageable. Wheatgrass juice is a fast and sure way to cleanse the body from environmental pollutants. Its high levels of enzymes and amino acids work like a natural cleanser to detoxify the liver, eliminate toxic heavy metals from the blood stream, breaks impacted matter in the colon and rids the body of waste matter. ${ }^{9}$

Wheatgrass and chlorophyll are phytonutrients, which are rich in amino acids, protein, fiber, vitamins, minerals, and enzymes that work mutually to strengthen immunity. It builds up resistance to diseases, eliminates body toxins, and because of its alkaline properties, it is good for urinal problems. It stimulates metabolism and restores alkalinity of blood, its abundance of alkaline minerals helps reduce over acidity in the blood. ${ }^{10}$

\section{Beneficial effects of Wheat grass: cure for Teeth and Gum Diseases}

Japanese scientist's studies have shown that wheat grass can help in neutralizing and eliminating toxins from the body. It has the ability to destroy harmful germs and neutralizes bacteria. It prevents tooth decay and tooth aches. Lay pulp of wheatgrass soaked in juice and placing on diseased area in mouth or chewing of wheatgrass and spitting out the pulp ${ }^{11}$ helped reduce tooth decay. Wheat is valuable in the prevention and cure of pyorrhea. ${ }^{12}$ Rinsing the mouth with wheat grass helps in reducing the toxins in the gums, thereby improving the overall health ${ }^{13}$ the juice acts as an excellent mouth wash for sore throats and pyorrhea. It can be chewed with beneficial results.

Wheat grass is used for gingivitis and periodontal disease. The 1930's and 40's through to the present day, chlorophyll has captured the imagination of numerous scientists since its structure was determined much earlier by German scientist Richard Willstatter in 1913. According to Richard it could be fairly said that the history of wheatgrass or cereal grass healing could be attributed to chlorophyll. Researchers discuss the "anti-inflammatory, wound healing, and malodor-reducing properties of chlorophyllin" which is a derivative of chlorophyll. From clinical observation of many patients using wheatgrass extract, it can be vouched for a number of the remarkably effective healing outcomes. ${ }^{14}$ This is due to chlorophyll in low concentrations which acts on fibroblasts and assists in wound and injury healing both inside the body and on the skin and resulting in a "rapidly increased growth rate" - and marked increases in the rate of cell division. 
Wheatgrass has been shown to have potential antiinflammatory and anti-aging properties ${ }^{15}$ Ben et al, DeVogel et al, Ferruzia, and Blakesleeb have reported that regular ingestion of wheatgrass leaf extract improves the digestive system, and promotes general wellbeing. ${ }^{16,17}$ The major clinical utility of wheat grass in diseased conditions might be due to the presence of biologically active compounds and minerals in it and due to its antioxidant potential which is derived from its high content of bioflavonoids such as apigenin, quercitin, luteoline. Furthermore, indole compounds namely choline and laetrile present in it might be also responsible for its therapeutic potential. The presence of $70 \%$ chlorophyll, which is almost chemically identical to hemoglobin, in wheat grass makes it more useful in various clinical conditions involving hemoglobin deficiency and other chronic disorders. Goldberg. S 1943 conducted an experimental study on 300 cases of Vincents stomatitis and pyorrhea using water soluble chlorophyll and found it very beneficial. ${ }^{18}$ Hence the effects could be attributed to the high chlorophyll content present in the wheat grass extract.

\section{Wheatgrass in Cancer prevention}

There is a strong likelihood that wheatgrass extract, which contains chlorophyll, an antioxidant, may affect cancer prevention. Additionally, selenium and lactrile present in wheatgrass have anti-cancer properties. It is also thought to protect the body from the attack of cancer cells by making the walls of cancer cells more open to attack by white blood cells. ${ }^{19}$ Wheatgrass juice may also inhibit hematological toxicity related to chemotherapy in breast cancer patients. ${ }^{20}$ Wheatgrass and fiber methanol extracts have successfully exhibited to be cytotoxic towards HL60 cell lines without causing toxicity towards normal human Peripheral Blood Mononulear cell. Thus, these health products can be a potential alternative supplement for cancer patients. ${ }^{21}$

The benefits of Wheat grass Juice have been attributed to its high chlorophyll content in much of the anecdotal literature. Scientific studies regarding chlorophyll benefits have shown anti-cancer effects in animal models, and studies have been extended to human subjects. Two studies published in 2005 by de Vogel et al. found that chlorophyll inhibited haeminduced cytotoxicity and reduced epithelial cell turnover (hypoproliferation) in rat colons; the first article published in 2005a found this effect to be specific to natural chlorophyll. The Maxillofacial surgeons of the Hungarian association published a report on the use of fermented wheat germ product called Avemar and found it as an important adjunct in managing the oral cavity tumors. ${ }^{22}$ Another study by Karadan and colleagues 2007 showed that wheat grass is capable of inhibiting leukemic cells. ${ }^{23}$

\section{Hepatoprotective role of wheatgrass}

Jain et al reported the hepatoprotective role of fresh wheatgrass juice has in $\mathrm{CCl} 4$ treated rats. It showed a significant hepatoprotective effect with a dose of $100 \mathrm{mg} / \mathrm{kg} /$ day in terms of SGOT, SGPT, ALP and Bilirubin in serum. ${ }^{24}$

\section{Wheatgrass as cardio protective and anti- hyperlipidemic agent}

Chlorophyll, abundant in wheatgrass, increases the function of heart. Wheatgrass has been claimed to reduce the blood pressure as it enhances the capillaries, supporting the growth of lactobacilli. ${ }^{25}$

\section{Wheatgrass and Diabetes}

Wheatgrass powder has shown good improvement in resolving digestive system problems, (Diabetes) in particular. Abundance of natural fiber in wheatgrass optimizes blood sugar levels. The presence of chlorophyll, which is believed to be the pharmacologically active component in wheatgrass, acting as an anti-diabetic agent. ${ }^{1}$

\section{Wheatgrass and Rheumatoid Arthritis}

In a study when $8.5 \mathrm{~g}$ of fermented wheatgrass extract (Avemar) taken twice per day with water, in case of 15 Severe Rheumatoid Arthritis patients This may be due to presence of wheatgrass which contains 
vitamins $\mathrm{A}, \mathrm{B} 1, \mathrm{~B} 2, \mathrm{~B} 3, \mathrm{~B} 5, \mathrm{~B} 6$ and B12, vitamin $\mathrm{C}, \mathrm{E}$ and $\mathrm{K}$, Calcium, Iodine, Selenium, Zinc, and many other minerals, including, superoxide dismutase, muco-polysaccarides, and chlorophyll. The antiinflammatory properties exert a positive effect on bone and joint problems, reducing pain and swelling. ${ }^{26}$ The anecdotal literature says that WGJ has antimicrobial properties, inhibiting the growth of microorganisms. But there appears to be a lack of published scientific data on this topic, highlighting an area for continued research. Further studies testing on a wide range of pathogens against wheatgrass extracts would provide useful information and assist in our understanding and knowledge of the efficacy and actions of antimicrobial plant extracts.

\section{CONCLUSION}

Due to the encouraging experiences on the effects of wheat grass towards the antimicrobial effects and the cumulative resistance to antibiotics by many bacteria it has lead to the development of new antiseptics and antimicrobial agents is of growing interest (Weckesser et al. 2006). Plants that posses antimicrobial properties and thousands of constituents are valuable sources of new and biologically active molecules (Das et al. 2010); including a wide variety of secondary metabolites, such as tannins, terpenoids, alkaloids, and flavonoids, which have been found to have antimicrobial properties in-vitro (Cowan, 1999). These products are of interest as a source of safer or more effective substitutes to synthetically produced antimicrobial agents (Mullen et al. 2012). High content of bioflavonoids (Padalia et al. 2010) in WGJ may contribute towards antimicrobial effects as a supplement and evidence in the literature suggest this supplement does possess some efficacy towards microbial pathogens.

Screening against a range of different microorganisms, using different extraction methods would provide more data, thus contributing towards the knowledge on this topic.. The well being of an individual can be reflected by the oral health status as dental diseases are often symptoms in many cases a warning signs of serious health problems that would come in the near future. Thus, it should be made part of daily dietary intake in order to explore its maximum benefits.

\section{REFERENCES}

1. Jarvis, William (2001-01-18). "Wheatgrass Therapy". The National Council Against Health Fraud.

2. Fahey JW, stephensonkk, dinkova-kostova at, egner pa, kenslertw, talalay p. Chlorophyll, chlorophyllin and related tetrapyrroles are significant inducers of mammalian phase 2cytoprotective genes. Carcinogenesis 2005;26(7):12471255.

3. DeVogel J, Denize SML, Jonker TM, Katan MB, Meer R van der: Natural chlorophyll but not chlorophyllin prevents hemeinduced cytotoxic and hyperproliferative effect in rat colon. J Nutr 2005,135: 1995-00.

4. Healthy Benefits of Wheat Grass (Online). Available from: URL:http://www.ph-ion.com/index.asp?PageAction $=$ Custom $\& \mathrm{ID}=32$.

5. Kulkarni SD, Acharya R, Nair AG, Reddy AVR. Determination of elemental concentration profiles in tender wheat grass (triticumaestivum L. using instrumental neutron activation analysis. Food Chemistry 2006; 4: 699-707.

6. Swati P, Sushma D, Indira R, Alka G, Mamta D. Multitude potential of Wheat grass Juice (Green Blood): An overview. Chronicles of Young Scientist 2010; 1(2):23-28.

7. Bar-sella P. Rejunvention- Health According to Dr. Ann Wigmore's Teachings. Kiryat Ono. Israel: Shachar Ltd, (in Hebrew) 1998:142-152.

8. Fahey, Jed W, Katherine K, Stephenson, Albena T, Kostova D, Patricia A, Egner, Thomas W, Kensler and Talalay P: "Chlorophyll, chlorophyllin and related tetrapyrroles are significant inducers of mammalian phase 2 cytoprotective genes". Carcinogenesis (Oxford University Press) 2005,6 (7): 1247-1255.

9. Wheat J, Currie J: Herbal medicine for cancer patients: An evidence based review. The Internet Journal of Alternative Medicine 2008, 5: 28-30

10. "Nutrition Facts and Analysis for wheat grass". Nutrition Data. Retrieved 11 December 2013.

11. Ben A E, Goldin E, Wengrower D, Stamper A, Kohn R, Berry $\mathrm{E}$ : Wheat grass juice in the treatment of active distal ulcerative colitis: a randomized double-blind placebo-controlled trial. Scand J Gastroenterol 2002, 37: 444-449. 
12. Taheri JB, Azimi S, Refieian N, Zanjani HA. Herbs in dentistry. Int Dent J.2011, Dec, 61(6); 287-96.

13. Durairaj VHoda M, Shakya G, Babu SP, Rajagopalan R. Phytochemical screening and analysis of antioxidant properties of aqueous extract of wheatgrass. Asian Pac J Trop Med.2014;sep;751:5398-404.

14. Smith BH: Generalization of spatially variant apodization to nonintegralNyquist sampling rats. IEEE Trans Image Process 2000, 9:1088-1093.

15. Chris Reynolds. Articles on Wheatgrass Healing/ Wheatgrass Healing - A Brief Scientific Review

16. Food Science and Quality Management ISSN 2224-6088 (Paper) ISSN 2225-0557 (Online) Vol2,2011.

17. Wigmore A. The wheat grass Book, New York. Avery Publishing group 1986.

18. Goldberg S.1943.Am.J.Surg.1943;62:117-123

19. Sandstrom PA, Mannie MD, Buttke TM: Inhibition of activation-induced death in $\mathrm{T}$ cell hybridomas by thiolantioxidants: oxidative stress as a mediator of apoptosis. J LeukocBiol 1994,55: 221-226.
20. BarSela G, Tsalic M, Fried G, Goldberg H: Wheat grass juice may improve hematological toxicity related to chemotherapy in breast cancer patients. Nutr Cancer. 2007, 58(1): 43-48.

21. NoorjahanBanuAlitheen, Chuah Li Oon, YeapSweeKeong, Tan KeeChuan, Ho Ket Li And Ho Wan Yong: Cytotoxic Effects Of Commercial Wheatgrass And Fiber Towards Human Acute Promyelocytic Leukemia Cells (H160). Pak. J. Pharm. Sci. 2011, 24(3): 243-250.

22. Borabas, J.,Nemeth, ZS, Hungarian Med. J. (OrvosiHetilap) 2006;174(35):1709-11

23) Karadag, A. et al. Anti proliferative and apoptotic effects of wheat grass (Triticum aestivum L)extract onchronic myeloid leukemia (CML) cell line. Planta Med 2007;73

24. Jain G, Argal A, Pathak A.K, Singh V.K, Kannojia P: Hepatoprotective activity of wheatgrass juice. The pharmacist 2007, 2(1) 29-30.

25. Locniskar M. (1988). Nutrition today. 3:37.

26. T. Nenonen,. Helve T, Rauma T, Nninen H: uncooked, Lactobacilli-Rich, Vegan Food And Rheumatoid arthritis. British Journal OfRheumatology 1998; 37:274-281.

Source of Support: Nil, Conflict of Interest: None Declared 